\title{
PADRÃO ESPAÇO-TEMPORAL DA UMIDADE VOLUMÉTRICA DO SOLO EM UMA BACIA HIDROGRÁFICA COM PREDOMINÂNCIA DE LATOSSOLOS ${ }^{(1)}$
}

\author{
Léo Fernandes Ávila ${ }^{(2)}$, Carlos Rogério de Mello ${ }^{(3)}$, José Márcio de Mello ${ }^{(4)} \&$ \\ Antônio Marciano da Silva ${ }^{(5)}$
}

\begin{abstract}
RESUMO
A umidade volumétrica do solo possui alta variabilidade espacial e temporal devido à influência de vários fatores ambientais e de uso do solo. Desse modo, seu entendimento assume papel fundamental na modelagem dos processos que envolvem o escoamento superficial, a erosão do solo e o transporte de sedimentos. Nesse contexto, objetivou-se neste estudo avaliar o padrão espacial e temporal da umidade volumétrica na camada superficial do solo, nas diferentes estações do ano, em uma bacia hidrográfica experimental, com predominância de latossolos, localizada na região Sul de Minas Gerais. Para isso, utilizou-se o conceito de estabilidade temporal e escalonamento de semivariogramas, o qual possibilitou a comparação da estrutura espacial dos modelos de semivariogramas ajustados. Foi possível detectar forte dependência espacial da umidade do solo na bacia hidrográfica, com grau de dependência sempre acima de $80 \%$, e os semivariogramas escalonados mostraram semelhanças no padrão espacial no verão e no outono e diferenças em relação ao inverno e à primavera. Dessa forma, constatou-se que houve diferença no padrão espacial da umidade do solo ao longo do ano, contudo maior homogeneidade no período chuvoso (verão). Ocorreu variação no padrão temporal de umidade do solo de acordo com as estações do ano, sendo verificada tendência nos dados de inverno e primavera, demonstrada pelo teste de Spearman. Devido às diferenças verificadas no padrão espaçotemporal da umidade do solo ao longo das estações do ano, quatro pontos distintos foram identificados, um em cada estação, para implantação de monitoramento permanente desse atributo do solo na bacia hidrográfica.
\end{abstract}

Termos de indexação: estabilidade temporal, estrutura da variabilidade espacial, semivariograma, umidade do solo.

\footnotetext{
(1) Recebido para publicação em 23 de dezembro de 2010 e aprovado em 15 de junho de 2011.

(2) Doutorando - PPGRH, Departamento de Engenharia da Universidade Federal de Lavras - UFLA. Caixa Postal 3037, CEP $37200-$ 000 Lavras (MG). Bolsista do CNPq. E-mail: avila_lf@posgrad.ufla.br

(3) Professor Adjunto, Departamento de Engenharia, UFLA. E-mail: crmello@deg.ufla.br

(4) Professor Adjunto do Departamento de Ciências Florestais, UFLA. E-mail: josemarcio@dcf.ufla.br

(5) Professor Titular, Departamento de Engenharia, UFLA. E-mail: marciano@deg.ufla.br
} 


\title{
SUMMARY: SPATIAL AND TEMPORAL PATTERNS OF SOIL MOISTURE IN A WATERSHED WITH PREDOMINANCE OF OXISOLS
}

\begin{abstract}
The spatial and temporal variability of soil moisture is high due to the influence of several environmental features and the land-use. The understanding of this variability plays a fundamental role in the modeling of surface runoff, soil erosion and sediment transport. This study aimed to evaluate the spatial and temporal patterns of surface soil moisture over the annual seasons, in a watershed with predominance of Oxisols in the south of the State of Minas Gerais. For this purpose, the temporal stability concept was used as well as semivariogram models to compare the spatial structure of the adjusted semivariogram models. It was possible to detect a strong spatial dependence of soil moisture in the watershed, with a spatial dependence degree of $>80 \%$. Besides, spatial pattern of the scaled semivariograms was similar for summer and fall, and different for winter and spring. Based on these results, the spatial patterns of soil moisture differed over the year, and were most homogenous in the rainy season (summer). Differences in the temporal patterns of soil moisture according to the season were verified, and also, the Sperman Test demonstrated a temporal bias in soil moisture $i$ winter and spring.
\end{abstract}

Index terms: temporal stability, spatial structure variability, semivariogram, soil moisture.

\section{INTRODUÇÃO}

A umidade do solo desempenha papel importante nos processos hidrológicos de superfície e transporte de sedimentos devido à sua relevante participação na separação da precipitação em infiltração e escoamento superficial. Além disso, exerce influência na interação solo-atmosfera, especialmente na evapotranspiração e na interferência dos processos vinculados à erosão hídrica, sendo, portanto, de grande utilidade para extensa faixa de aplicações visando à conservação do solo e da água.

No contexto geral de estudos hidrossedimentológicos, especialmente os vinculados à modelagem em bacias hidrográficas, a umidade do solo tem sido considerada, na maioria das aplicações, constante em toda a bacia hidrográfica (van den Elsen et al., 2003; Western et al., 2004). No entanto, possui alta variabilidade no espaço e no tempo, em face da influência de diversos fatores estáticos e dinâmicos do solo, além da interferência das mudanças sazonais no regime de chuvas. Nesse aspecto, é relativamente complexo descrever os processos ou fatores dominantes que podem influenciar na variabilidade espaçotemporal da umidade do solo, devido à heterogeneidade e à diversidade das condições ambientais envolvidas.

A variabilidade espacial da umidade do solo tem sido estudada por vários pesquisadores (Paz González et al., 2000; Gómez-Plaza et al., 2001; Western et al., 2004; Timm et al., 2006; Avila et al., 2010a; Mello et al., 2011), bem como a variabilidade temporal da umidade do solo em função das estações do ano (Grayson et al., 1997; Famiglietti et al., 1998; Western et al., 1998; Western \& Blöschl, 1999; Goméz-Plaza et al., 2000). No entanto, nota-se grande diversidade nos resultados, o que demonstra a carência de estudos conduzidos sob as mais diversas condições edafoclimáticas.

Atualmente, a geoestatística vem sendo amplamente utilizada para identificar e definir a estrutura espacial da umidade do solo (Western et al., 2004; Hébrard et al., 2006; Brocca et al., 2007; Zhu \& Shao, 2008). Essa ferramenta permite quantificar a estrutura espacial, possibilitando inferências sobre o padrão espacial da umidade do solo a partir da modelagem dos semivariogramas empíricos.

A modelagem de semivariogramas, além de possibilitar a identificação e definição da estrutura espacial, também permite sua comparação em diferentes datas de medição, a partir do escalonamento dos semivariogramas. Esse procedimento pode ser utilizado visando à comparação do padrão da estrutura da variabilidade espacial de diferentes propriedades, bem como a comparação de uma mesma propriedade em diferentes regiões.

O conceito de estabilidade temporal, introduzido por Vachaud et al. (1985), remete à ideia na qual alguns pontos de monitoramento apresentam valores semelhantes à média do total de pontos monitorados. Contudo, segundo Gómez-Plaza et al. (2000), esse conceito tem que ser analisado num maior número de ambientes e em diferentes escalas. Avila et al. (2010b), estudando a variabilidade espacial da umidade superficial do solo ao longo do tempo, em diferentes situações de uso do solo na região da Serra da Mantiqueira, MG, observaram que os pontos semelhantes ao comportamento médio da área, ou seja, os pontos escolhidos para posterior monitoramento, 
diferiram-se em relação aos períodos seco e chuvoso, além de verificar diferenças da estabilidade temporal em função do uso do solo. Vieira et al. (2010), num estudo semelhante, observaram variações no intervalo entre amostras para caracterização da variabilidade espacial e da estabilidade temporal do conteúdo de água no solo como função do seu uso.

Estudos realizados por Mello et al. (2011) na região da Serra da Mantiqueira (MG) e Western et al. (2004) em uma bacia hidrográfica com características semiáridas na Austrália apontaram que o padrão da umidade do solo é regido em função do período analisado, com influência importante das condições edafoclimáticas. Assim, de acordo com Moore et al. (1998), durante o período úmido, quando a precipitação excede a evapotranspiração, o padrão é dominado pelo movimento lateral da água, tanto na superfície quanto na subsuperfície, sendo a topografia o fator dominante. No entanto, segundo Hébrard et al. (2006), no período seco, quando a evapotranspiração excede continuamente a precipitação, as condições de demanda atmosférica são dominantes do padrão espacial do conteúdo de água no solo, sendo esse padrão reflexo das diferenças de uso e das classes de solo, tendo aparência mais aleatória. Nesse sentido, a estrutura de continuidade espacial da umidade do solo, a qual descreve seu padrão espacial, pode variar ao longo do ano, especialmente em regiões onde há forte concentração da precipitação em determinado período, uma vez que os fatores que controlam a umidade do solo estão associados às condições climáticas predominantes. Além disso, no contexto do padrão temporal espera-se que também haja variabilidade importante ao longo do ano, pelo mesmo motivo destacado anteriormente, ou seja, devido às características climáticas e às condições de uso do solo na bacia hidrográfica.

Nesse contexto, o objetivo deste trabalho foi avaliar o padrão espacial e temporal da umidade do solo nas quatro estações do ano, em uma Bacia Hidrográfica representativa dos Latossolos, localizada na região Sul do Estado de Minas Gerais.

\section{MATERIAL E MÉTODOS}

A área de estudo, denominada bacia hidrográfica do ribeirão Marcela, encontra-se próxima ao município de Nazareno, Sul de Minas Gerais. Possui uma área de drenagem de $470 \mathrm{ha}$, situando-se entre as coordenadas UTM "550169" e "552810" de longitude W e “7650163" e "7650989" de latitude S e está inserida na Unidade de Planejamento e Gestão de Recursos Hídricos (UPGRH) do Alto Rio Grande (GD1).

Segundo Motta et al. (2001), essa bacia hidrográfica é constituída pelas seguintes unidades pedológicas: Latossolo Vermelho-Amarelo distrófico típico (LVAd); Latossolo Vermelho distrófico típico (LVd); Cambissolo Háplico distrófico (CXbd); e Neossolo Flúvico distrófico
(RUd) (Figura 1a). No quadro 1, apresenta-se a distribuição das unidades pedológicas da bacia hidrográfica do ribeirão Marcela.

De acordo com Motta et al. (2001), como os Latossolos ocupam 79 \% da área da bacia e são expressivos na região Sul de Minas Gerais, essa bacia hidrográfica representa, de forma ímpar, as condições pedológicas vinculadas a esses solos, correspondendo a uma unidade fisiográfica experimental representativa da região. Devido a esse aspecto, a bacia hidrográfica do ribeirão Marcela encontra-se em monitoramento hidrossedimentológico e climático desde 2006.
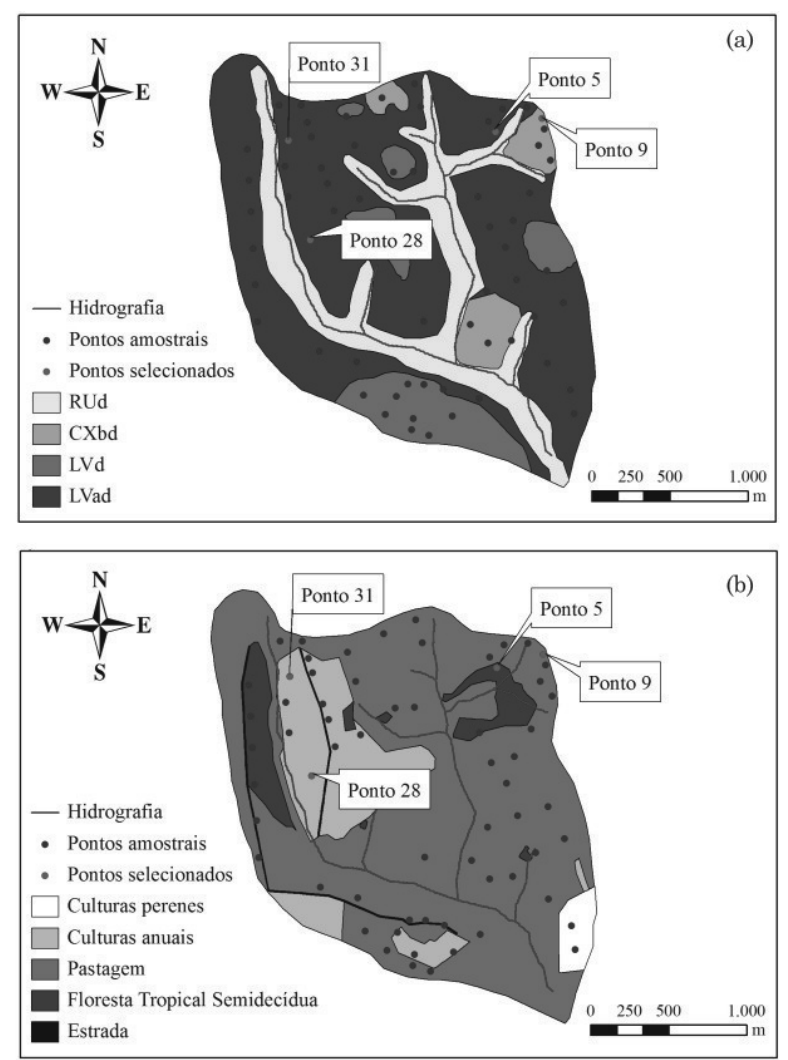

Figura 1. (a) Distribuição espacial dos solos e (b) mapa de uso do solo (2008), com a localização dos pontos amostrais e dos pontos selecionados para o monitoramento da umidade superficial do solo na bacia hidrográfica do ribeirão Marcela.

Quadro 1. Distribuição das unidades pedológicas na bacia hidrográfica do ribeirão Marcela

\begin{tabular}{lc}
\hline \multicolumn{1}{c}{ Unidade Pedológica } & Percentual \\
\hline & $\%$ \\
Latossolo Vermelho-Amarelo distrófico típico (LVAd) & 65 \\
Latossolo Vermelho distrófico típico (LVd) & 14 \\
Cambissolo Háplico distrófico (CXbd) & 5 \\
Neossolo Flúvico distrófico (RUd) & 16 \\
\hline
\end{tabular}


Os usos atuais do solo na área da bacia correspondem a $76 \%$ de pastagem, $17 \%$ de culturas anuais, $3 \%$ de culturas perenes e $4 \%$ de Floresta Tropical Semidecídua (subcaducifólia). Na Figura 1b, apresenta-se o mapa de uso atual dos solos da bacia hidrográfica, obtida a partir da interpretação de imagem Allos de 2008, com o programa Envi (2000), seguida de validação em condições de campo. Nessa figura são mostrados também os pontos monitorados ao longo do período de análise (em azul). Os pontos em vermelho correspondem àqueles indicados, com base na análise desenvolvida no trabalho, para representar a média geral da bacia. Maiores detalhes sobre esses pontos em vermelho serão apresentados no item Resultados e Discussão.

O clima da região, como proposto por Köppen, é do tipo Cwa, com invernos secos e verões úmidos, sendo julho o mês mais seco e frio. Durante as estações de primavera e verão ocorrem as maiores precipitações, sendo, portanto, o período em que o solo se encontra com maior teor de água. Segundo Mello et al. (2007), a precipitação média anual na Bacia Hidrográfica do Ribeirão Marcela é de $1.570 \mathrm{~mm}$, com aproximadamente $80 \%$ do total ocorrendo no período entre novembro e março.

O monitoramento da umidade do solo foi realizado na camada superficial $(0-0,20 \mathrm{~m})$, no período entre maio de 2007 e maio de 2008, com periodicidade quinzenal de leituras, totalizando 63 pontos de medição. O monitoramento foi realizado utilizandose um equipamento portátil do tipo "Time Domain Reflectometry" (TDR), fabricado pela IMKO, modelo TRIME- FM, com hastes de 0,20 m de comprimento. A calibração do TDR foi realizada segundo van den Elsen et al. (2003), os quais trabalharam com equipamento semelhante. Desse modo, foram ajustados e analisados seis modelos matemáticos (linear, logarítmico, polinomial de $2^{\circ}$ grau, potencial, exponencial e média móvel) aos dados mensurados da umidade superficial do solo pelo equipamento TDR, associados aos valores observados da umidade do solo, obtidos inicialmente pelo método gravimétrico. Para isso, coletaram-se amostras indeformadas com amostrador de Uhland, as quais foram parafinadas e acondicionadas em filmes plásticos, objetivando preservar sua umidade, e posteriormente enviadas ao laboratório. Os valores de umidade foram então convertidos em umidade volumétrica com base na densidade do solo, a qual foi avaliada em cada ponto amostral de umidade, para posterior análise dos ajustes matemáticos propostos e identificação da melhor curva de calibração possível.

Os dados mensurados de umidade do solo foram inicialmente submetidos a uma análise exploratória, com o intuito de identificar tendências, valores discrepantes ("outliers") e dispersão dos dados, por meio de gráficos de tendência, histogramas de frequência e gráficos "boxplot", visando atender às premissas fundamentais estabelecidas pela geoestatística, especialmente a hipótese intrínseca (Journel \& Huijbrets, 1978; Isaaks \& Srivastava, 1989; Vieira, 2000).

Para avaliar e modelar a estrutura de dependência espacial dos dados em cada data de mensuração, foram aplicados os modelos teóricos de semivariogramas exponencial e esférico ajustados pelos métodos dos Mínimos Quadrados Ponderados (MQP) e Máxima Verossimilhança (MV), avaliando-se a qualidade do ajuste pelo critério do grau de dependência espacial (GD). Esse critério possibilita quantificar a estrutura de dependência espacial, sendo determinado pela razão entre a variância estrutural $\left(\mathrm{C}_{1}\right)$ e o patamar $\left(\mathrm{C}_{0}+\mathrm{C}_{1}\right)$. Adaptando a classificação proposta por Cambardella et al. (1994), o GD apresentou a seguinte classificação: $\leq 25 \%$ (fraco), entre 25 e $75 \%$ (moderado) e $>75 \%$ (forte).

Após a seleção, os semivariogramas foram escalonados e agrupados em um mesmo gráfico correspondendo a cada estação do ano (inverno, primavera, verão e outono), com vista a uma comparação da estrutura da variabilidade espacial do conteúdo de água no solo nas diferentes estações do ano.

Para realização da análise exploratória dos dados e modelagem e escalonamento dos semivariogramas, foi utilizado o software R (R Development Core Team, 2010), com o pacote geoestatística geoR (Ribeiro Júnior \& Diggle, 2001), ambos de livre acesso e de acordo com a licença GPL (General Public Licence).

Na avaliação da estabilidade temporal do conteúdo de água no solo foram utilizados dois índices: o coeficiente de posição de Spearman e a diferença relativa (Vachaud et al., 1985). A diferença relativa faz uma análise dos desvios entre os valores observados individualmente e a média destes, e o coeficiente de posição de Spearman indica o grau de concordância da variabilidade espacial obtida em diferentes tempos. O coeficiente de Spearman é dado por:

$$
\mathrm{cs}=1-\frac{6 \times \sum_{i=1}^{N}\left(F_{i}-f_{i}\right)^{2}}{N^{3}-N}
$$

em que $\mathrm{N}$ é o número de dados da série, $\mathrm{f}_{\mathrm{i}}$ corresponde à posição temporal da série histórica e $\mathrm{F}_{\mathrm{i}}$ compreende a posição em que as observações associadas a fi ocupam com a série histórica ordenada em ordem crescente.

O coeficiente de Spearman (cs) foi empregado para avaliar o grau de correlação da variabilidade espacial do conteúdo de água no solo nos diferentes tempos de amostragem. Um valor de cs igual à unidade corresponderá a posições idênticas em todos os pontos de medição, ou seja, estabilidade perfeita entre dois tempos. Nesse sentido, quanto mais próximo de 1 for cs, maior estabilidade apresentará o processo (Campos, 1983; Vachaud et al., 1985). A diferença relativa $\left(\bar{\delta}_{\mathrm{ij}}\right)$ pode ser calculada pela seguinte equação: 


$$
\bar{\delta}_{\mathrm{ij}}=\frac{\theta_{\mathrm{ij}}-\bar{\theta}_{\mathrm{j}}}{\bar{\theta}_{\mathrm{j}}}
$$

em que $\bar{\delta}_{\mathrm{ij}}$ é a diferença relativa média na posição i no tempo j; $\theta_{\mathrm{ij}}$ é o valor do conteúdo de água no solo na posição i e no tempo j; $\bar{\theta}_{\mathrm{j}}$ é a média do conteúdo de água no solo, em todas as posições, no tempo j.

Quando a diferença relativa apresentar pequena variação temporal entre as posições, há indicação de estabilidade temporal. A média no tempo dessa diferença relativa para cada posição i, ou diferença relativa média, associada ao respectivo desvio-padrão no tempo e ordenadas em ordem crescente, permite identificar posições que representam a média geral do conteúdo de água no solo com determinado nível de confiabilidade, assim como os valores sub e superestimados. Nesse sentido, a confiabilidade da estimativa da média geral do conteúdo de água no solo pela posição identificada ficará condicionada ao desvio-padrão, ou seja, quanto menor o valor do desviopadrão, maior a confiabilidade de se utilizar o referido ponto para estimar a média geral.

Após a determinação das diferenças relativas médias e dos respectivos desvios-padrão, plotaram-se os valores das diferenças relativas médias em ordem crescente associadas aos seus desvios-padrão, em cada estação do ano, visando identificar posições que representem a média geral do conteúdo de água no solo e analisar a variabilidade da dispersão dos dados nas diferentes estações do ano.

Com o objetivo de analisar a existência de tendências temporais na série histórica dos dados do conteúdo de água no solo, o teste de Spearman foi aplicado. As tendências temporais podem ocorrer devido a possíveis mudanças graduais no uso do solo, bem como à própria alteração de seu comportamento, ocasionados eventualmente pelo manejo do solo, podendo produzir alterações na estacionariedade da série histórica (Avila et al., 2010b). A estatística do teste de Spearman (T) pode ser obtida por:

$$
\mathrm{T}=\frac{\mathrm{cs}}{\sqrt{\operatorname{var}(\mathrm{cs})}}
$$

em que var (cs) é a variância do coeficiente de correlação de Spearman. Considerando um nível de significância de $5 \%(\alpha=0,05)$, pela Tabela de Z obtémse $\mathrm{Z}_{0,975}=1,96$. Assim, se $\mathrm{T}>\mathrm{Z}_{1-(\alpha / 2)}$, rejeita-se a hipótese $\mathrm{H}_{0}$ de que as observações não apresentam tendência temporal. A variância do coeficiente de correlação é obtida por:

$$
\operatorname{var}(\mathrm{cs})=\frac{1}{\mathrm{~N}-1}
$$

\section{RESULTADOS E DISCUSSÃO}

Na figura 2 está apresentado o modelo polinomial de $2^{\circ}$ grau aplicado à calibração da sonda TDR utilizada neste trabalho, uma vez que ele apresentou o melhor ajuste estatístico entre os modelos testados, com coeficiente de determinação ajustado consideravelmente elevado e significativo pelo teste de F. No trabalho realizado por van den Elsen et al. (2003) e Mello et al. (2011), os quais trabalharam com instrumento similar, os valores do ajuste das equações de calibração foram similares, e ambos estudaram o modelo polinomial de $2^{\circ}$ grau, classificando a calibração como boa e aceitável.

No quadro 2, apresentam-se os modelos de semivariogramas selecionados com os respectivos parâmetros de ajuste e o grau de dependência espacial. Observa-se, nesse quadro, que o GD na maioria dos casos foi de $100 \%$, com apenas duas exceções, sendo $83 \%$ seu menor valor. Com isso, é possível constatar forte estrutura de dependência espacial da umidade do solo na bacia hidrográfica estudada. Avila et al. (2010a), num estudo sobre modelagem da continuidade espacial da umidade do solo numa bacia hidrográfica da Serra da Mantiqueira, obtiveram resultados semelhantes, ou seja, constataram forte estrutura de dependência espacial da umidade do solo, com valor médio de GD de $88 \%$.

Analisando os valores do alcance teórico dos modelos selecionados (Quadro 2), verificaram-se valores entre 62 e $431 \mathrm{~m}$, havendo tendência dos maiores valores no inverno, período correspondente à época mais seca do ano, quando o solo se encontra com menor umidade. Entretanto, notou-se tendência de menores valores na primavera, quando ocorre o início do aumento do armazenamento de água no solo. A partir desse período, notadamente no final do mês de janeiro, observou-se aumento expressivo dos valores do alcance, com tendência de se estabilizar próximo a $200 \mathrm{~m}$ até o início do período seco (final de maio). Western et al. (1998), objetivando avaliar o padrão espacial da umidade do solo numa microbacia hidrográfica na Austrália, verificaram que os semivariogramas

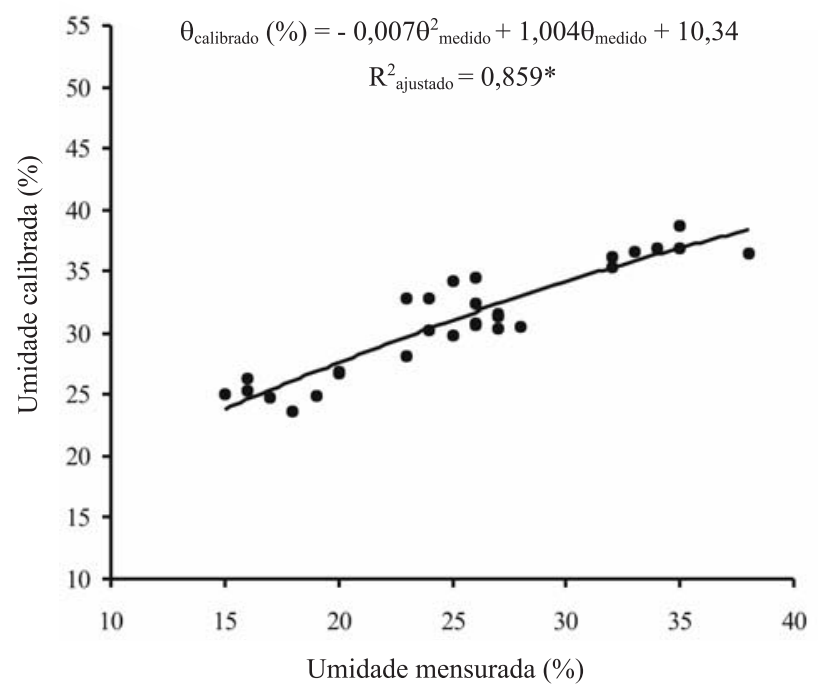

Figura 2. Modelo polinomial de $2^{\circ}$ grau ajustado para calibração da sonda TDR aos solos da bacia hidrográfica do ribeirão Marcela. 
Quadro 2. Seleção dos modelos de semivariogramas ajustados para cada leitura de umidade do solo com os respectivos parâmetros de ajuste (EP: efeito pepita; P: patamar; e A: alcance) e grau de dependência espacial (GD)

\begin{tabular}{rlllllrrr}
\hline \multirow{2}{*}{ Leitura } & Data & Modelo & Método & EP & P & A & GD \\
& & & & & & & \\
& & & & & & m & $\%$ \\
1 & $24 / 06 / 07$ & ESF & MQP & 0,00 & 2,07 & 287,35 & 100 \\
2 & $25 / 07 / 07$ & ESF & MQP & 0,00 & 20,88 & 431,76 & 100 \\
3 & $12 / 08 / 07$ & ESF & MQP & 0,00 & 20,32 & 231,18 & 100 \\
4 & $26 / 08 / 07$ & EXP & MQP & 0,15 & 4,33 & 349,65 & 97 \\
5 & $15 / 09 / 07$ & EXP & MV & 0,00 & 2,91 & 197,48 & 100 \\
6 & $20 / 09 / 07$ & EXP & MQP & 0,00 & 8,38 & 95,61 & 100 \\
7 & $13 / 10 / 07$ & EXP & MV & 0,00 & 2,06 & 129,39 & 100 \\
8 & $27 / 10 / 07$ & EXP & MQP & 0,00 & 6,99 & 111,03 & 100 \\
9 & $09 / 11 / 07$ & EXP & MV & 0,00 & 13,85 & 199,18 & 100 \\
10 & $22 / 11 / 07$ & EXP & MV & 0,00 & 10,64 & 103,95 & 100 \\
11 & $08 / 12 / 07$ & ESF & MV & 0,00 & 18,33 & 105,32 & 100 \\
12 & $21 / 12 / 07$ & EXP & MV & 0,00 & 23,94 & 130,62 & 100 \\
13 & $26 / 01 / 08$ & ESF & MV & 0,00 & 11,38 & 204,25 & 100 \\
14 & $09 / 02 / 08$ & ESF & MV & 0,00 & 14,28 & 307,03 & 100 \\
15 & $24 / 02 / 08$ & EXP & MV & 0,00 & 49,18 & 185,54 & 100 \\
16 & $09 / 03 / 08$ & EXP & MQP & 4,05 & 23,95 & 209,06 & 83 \\
17 & $23 / 03 / 08$ & EXP & MQP & 0,00 & 30,60 & 258,68 & 100 \\
18 & $04 / 04 / 08$ & EXP & MQP & 0,00 & 78,56 & 208,61 & 100 \\
19 & $20 / 04 / 08$ & EXP & MQP & 0,00 & 19,12 & 220,19 & 100 \\
20 & $02 / 05 / 08$ & ESF & MV & 0,00 & 18,63 & 231,60 & 100
\end{tabular}

MQP: Mínimos Quadrados Ponderados; ESF: Modelo Esférico; EXP: Modelo Exponencial.

apresentaram diferenças importantes de acordo com as estações do ano. Esse fato sugere que para um adequado planejamento amostral, visando ao monitoramento da umidade do solo, é importante que sejam consideradas as condições do período de monitoramento, uma vez que houve diferenças significativas no alcance teórico nas diferentes estações do ano. Essa situação evidencia que se deve adotar um menor intervalo entre amostras no período de aumento do armazenamento de água no solo (início do período chuvoso) em relação ao período seco.

Na figura 3 estão apresentados os semivariogramas escalonados para a umidade do solo, em cada estação do ano (inverno, primavera, verão e outono). Pela análise dos semivariogramas, verificou-se maior similaridade no ajuste dos modelos para leituras durante o verão (Figura 3c) e outono (Figura 3d). Nos primeiros, notou-se que, comparativamente, os parâmetros de ajuste do modelo exponencial (leituras 15 e 16) foram idênticos e, no modelo esférico (leituras 13 e 14), ligeiramente semelhantes, ou seja, possuem praticamente a mesma região de influência em que a umidade do solo se apresenta espacialmente dependente, indicando uniformidade na estrutura de dependência espacial. No outono, o ajuste dos modelos exponenciais também foi similar (leituras 17, 18 e 19), com exceção do modelo esférico (Leitura 20). É importante destacar que o comportamento do modelo esférico se difere do modelo exponencial, e o primeiro apresenta crescimento rápido na origem e atinge o patamar a uma distância finita, enquanto o segundo alcança o patamar somente assintoticamente.

Na primavera (Figura 3b), período em que ocorre aumento do armazenamento de água no solo, o ajuste dos quatro modelos exponenciais foi semelhante (leituras 7, 8,10 e 11), havendo pequena diferença no ajuste do modelo exponencial referente à mensuração número 9, o que indica, contudo, boa aproximação em relação aos demais ajustes.

No inverno (Figura 3a), comparando separadamente o ajuste dos modelos esférico (leituras 1, 2 e 3) e exponencial (4, 5 e 6$)$, notou-se maior diferença, especialmente no tocante ao alcance dos semivariogramas, evidenciando que há diferenças na estrutura da variabilidade espacial da umidade do solo ao longo dessa estação.

De modo geral, notou-se melhor aproximação no ajuste dos modelos de semivariograma no verão e no outono, quando comparado com o inverno e a primavera, indicando que, quando o solo tem menor umidade, os modelos apresentam diferenças importantes na estrutura de dependência espacial. Segundo Grego et al. (2006), a maior variabilidade da estrutura de dependência espacial no período seco ocorre provavelmente devido ao processo de secagem do solo, e ocasionalmente podem aparecer algumas fissuras no solo, aumentando a aleatoriedade da variação espacial. Outro fato que deve ser destacado é que, quando a umidade do solo for baixa, outros fatores passam a influenciá-la, com maior participação na aleatoriedade da variação espacial. Além desses aspectos, durante o inverno (período seco) a evapotranspiração dominou o comportamento da umidade do solo e, como havia considerável variabilidade de uso do solo na bacia para as espécies que possuíam sistema radicular raso (pastagens), sua demanda evapotranspirativa era mais acentuada; isso também foi notado nas espécies de grande porte, uma vez que elas absorvem água em camadas bem mais profundas no solo. Todos esses aspectos sugerem que o padrão de estrutura da dependência espacial da umidade do solo se altera em função da época do ano nas condições edafoclimáticas da bacia hidrográfica estudada, ou seja, no período seco havia maior diferenciação na estrutura de dependência espacial.

No quadro 3 são apresentados os valores da estatística do teste de Spearman, coeficiente de correlação de Spearman e as lâminas de precipitação pluvial acumuladas entre uma medição e outra imediatamente anterior na bacia hidrográfica. Considerando o nível de significância de $5 \%$, observouse que as séries de dados de umidade do solo, no verão (leituras 13 a 16), não apresentaram significância pelo Teste de Spearman, ou seja, pode-se aceitar a hipótese $\mathrm{H}_{0}$ de que os dados não apresentam tendência temporal. No entanto, na primavera (leituras 7 a 12) 


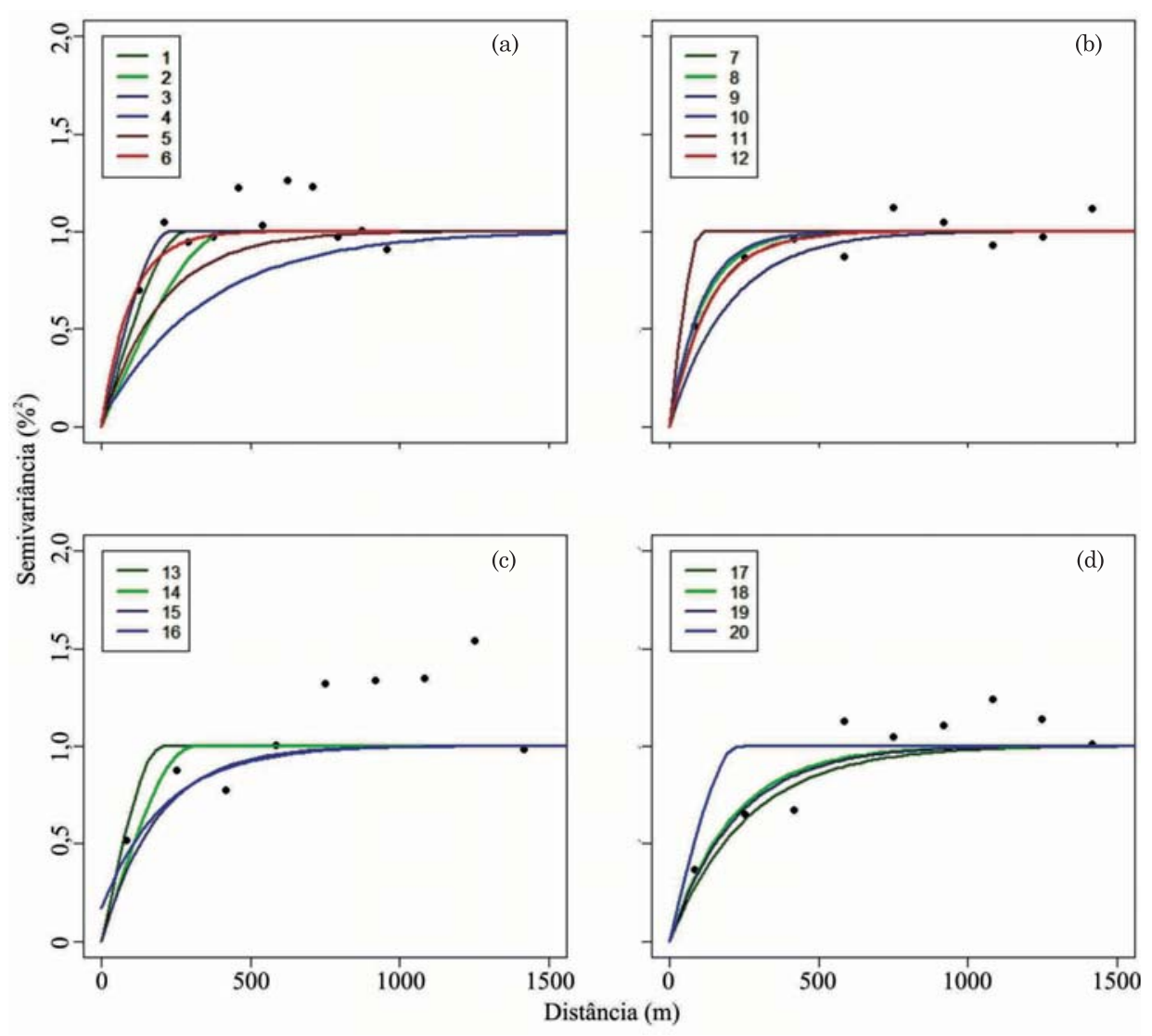

Figura 3. Semivariogramas escalonados para inverno (a), primavera (b), verão (c) e outono (d).

há significância da estatística do teste, ou seja, nesse nível de probabilidade se deve rejeitar a hipótese $\mathrm{H}_{0}$, indicando que, nesse período, há tendência temporal. No inverno (leituras 1 a 6 ) foram constatados quatro eventos para os quais a hipótese de nulidade pôde ser rejeitada, ou seja, com os dados apresentando tendência temporal (4 das 6 leituras). Finalmente, no outono (leituras 17 a 20), verificou-se apenas um evento com significância estatística do teste. Com base nesses resultados, constatou-se que as séries de umidade do solo apresentaram tendência temporal no inverno (estação mais seca) e na primavera (época de reumedecimento do solo). Em contrapartida, no verão (época em que há maior umidade do solo) e outono (período em que se inicia a redução da umidade do solo), as séries de umidade do solo não apresentaram tendência temporal.

Analisando os coeficientes de correlação de Spearman (cs), observou-se variação significativa dos valores de cs em relação ao tempo, apresentando maiores valores no verão e outono, o que indica maior estabilidade do processo nesses períodos. Entretanto, verificou-se que os menores valores de cs ocorreram nas estações de inverno e primavera, indicando baixa correlação da umidade do solo na escala temporal. Nesse contexto, constatou-se que no período em que ocorre maior concentração de precipitação pluvial, ou
Quadro 3. Estatística do teste de Spearman (T), coeficiente de correlação de Spearman (cs) em diferentes datas de amostragem e lâmina de precipitação pluvial acumulada $(P)$ durante o respectivo período de monitoramento da umidade do solo

\begin{tabular}{rrrrr}
\hline Leitura & Data & $\mathbf{P}$ & $\mathbf{T}$ & $\mathbf{c s}$ \\
\hline 1 & $24 / 06 / 07$ & & $-1,58^{\mathrm{ns}}$ & $-0,25$ \\
2 & $25 / 07 / 07$ & 21 & $-0,71^{\mathrm{ns}}$ & $-0,09$ \\
3 & $12 / 08 / 07$ & 7 & $-2,76^{*}$ & $-0,36$ \\
4 & $26 / 08 / 07$ & 0 & $-3,84^{*}$ & $-0,49$ \\
5 & $15 / 09 / 07$ & 0 & $-4,03^{*}$ & $-0,51$ \\
6 & $20 / 09 / 07$ & 19 & $-2,87^{*}$ & $-0,36$ \\
7 & $13 / 10 / 07$ & 0 & $-4,17^{*}$ & $-0,53$ \\
8 & $27 / 10 / 07$ & 87 & $-4,60^{*}$ & $-0,58$ \\
9 & $09 / 11 / 07$ & 46 & $-4,32^{*}$ & $-0,55$ \\
10 & $22 / 11 / 07$ & 66 & $-2,61^{*}$ & $-0,33$ \\
11 & $08 / 12 / 07$ & 47 & $-3,46^{*}$ & $-0,44$ \\
12 & $21 / 12 / 07$ & 118 & $-1,75^{*}$ & $-0,22$ \\
13 & $26 / 01 / 08$ & 257 & $0,34^{\mathrm{ns}}$ & 0,05 \\
14 & $09 / 02 / 08$ & 193 & $0,62^{\mathrm{ns}}$ & 0,09 \\
15 & $24 / 02 / 08$ & 92 & $0,41^{\mathrm{ns}}$ & 0,06 \\
16 & $09 / 03 / 08$ & 94 & $-1,41^{\mathrm{ns}}$ & $-0,21$ \\
17 & $23 / 03 / 08$ & 186 & $-0,16^{\mathrm{ns}}$ & $-0,02$ \\
18 & $04 / 04 / 08$ & 55 & $2,44^{*}$ & 0,38 \\
19 & $20 / 04 / 08$ & 120 & $1,60^{\mathrm{ns}}$ & 0,22 \\
20 & $02 / 05 / 08$ & 14 & $-0,51^{\mathrm{ns}}$ & $-0,08$ \\
\hline
\end{tabular}

ns: não significativo; *: significativo a $5 \%$. 
seja, período em que há maior umidade no solo, há também maior estabilidade temporal, comparável à estação seca.

Analisando os resultados observados nos semivariogramas escalonados associados aos valores de cs, é possível inferir que no inverno (menor umidade no solo) e na primavera (no período de aumento da umidade) ocorre participação significativa de outros atributos do solo e das condições atmosféricas, influenciando na aleatoriedade da variabilidade espacial e na baixa correlação da umidade do solo na escala temporal. Grayson et al. (1997) relataram que, quando a evapotranspiração supera continuamente a precipitação, o padrão de umidade do solo é fortemente variável e heterogêneo. Nesse aspecto, alguns estudos indicam que os fatores que influenciam os fluxos de água no solo no período seco são: declividade (Moore et al., 1998; Gomez-Plaza et al., 2001; Qiu et al., 2001); orientação da vertente (Moore et al., 1998; Famiglietti et al., 1998); e textura, estrutura do solo e conteúdo de matéria orgânica, os quais modificam a condutividade hidráulica do solo (Canton et al., 2004) e o tipo de vegetação (Mohanty et al., 2000; Qiu et al., 2001).

Na figura 4, apresentam-se as diferenças relativas médias associadas aos respectivos desvios-padrão das diferentes estações do ano. Verificam-se, nessa figura, percentuais menores que $30 \%$ no inverno e na primavera. No verão, a diferença relativa média foi de aproximadamente $80 \%$, enquanto no outono esse percentual foi de $60 \%$. No inverno, primavera e outono, os valores encontrados foram semelhantes aos obtidos por Gómez-Plaza et al. (2000), que obtiveram diferenças relativas superiores a $60 \%$ em ambiente semiárido, com alta participação da evapotranspiração no comportamento da umidade do solo.

Analisando os valores do desvio-padrão, observouse, tanto no verão quanto no outono, menor homogeneidade nos valores do desvio-padrão, ou seja, maior dispersão da diferença relativa média dos pontos monitorados se comparável ao inverno e à primavera, indicando que esse comportamento está associado à maior umidade do solo no verão e no início do outono. Avila et al. (2010b), analisando a estabilidade temporal da umidade superficial do solo sob diferentes usos (Mata Atlântica, pastagem e vegetação de várzea), concluíram que na vegetação de várzea, mesmo na estação seca, há maior dispersão da diferença relativa média e tal comportamento está relacionado à maior umidade do solo nessa condição de seu uso, comparável aos demais ambientes. Segundo esses mesmos autores, esse comportamento ocorre provavelmente devido à influência pronunciada da condutividade hidráulica, a qual é sensivelmente reduzida com pequenas reduções da umidade do solo. Nesse aspecto, pode-se inferir que a maior dispersão das diferenças relativas se deve à maior umidade do solo, que por sua vez sofre influência da condutividade hidráulica. (a)

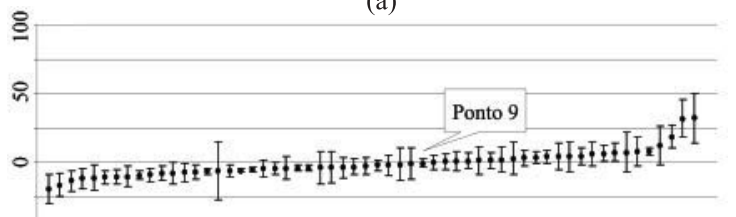

ติ

8

\&

(b)
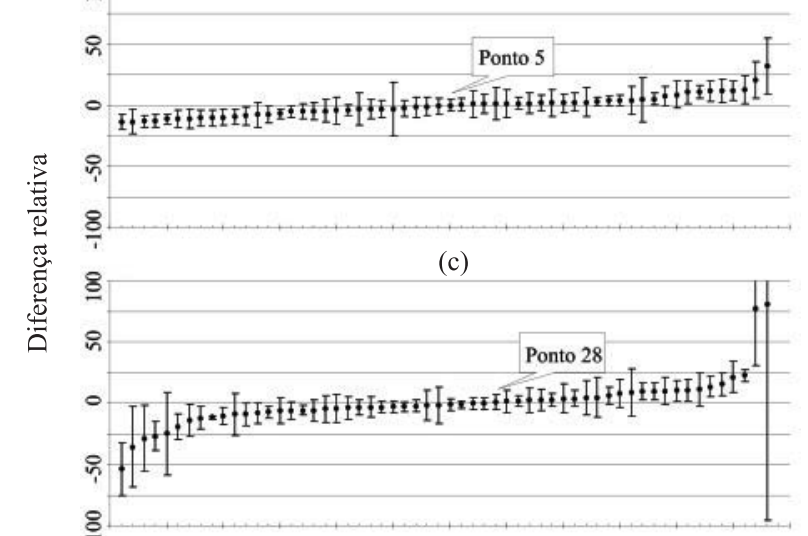

\&.

(d)

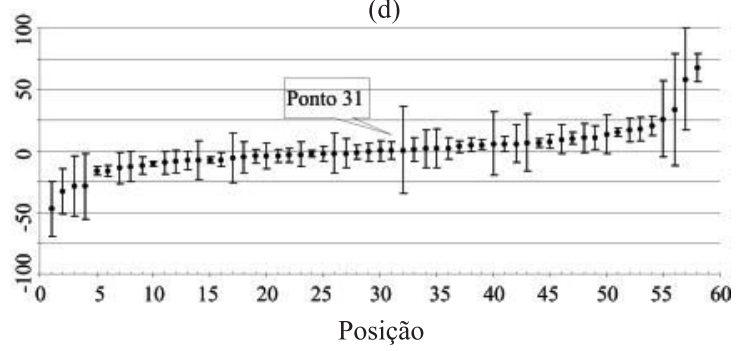

Figura 4. Diferenças relativas médias e respectivos desvios-padrão da umidade do solo (\%) nas estações de inverno (a), primavera (b), verão (c) e outono (d).

Confrontando os resultados dos alcances teóricos dos modelos de semivariogramas ajustados (Quadro 1), constataram-se menores valores dos alcances na primavera, próximos a $100 \mathrm{~m}$. Desse modo, pode-se inferir que há necessidade de aumentar a quantidade de amostras de umidade do solo no período chuvoso, especialmente no verão, de forma a diminuir a dispersão das diferenças relativas e, consequentemente, proporcionar melhores condições para seu posterior mapeamento.

Com relação aos pontos escolhidos para monitoramento contínuo da umidade do solo na bacia hidrográfica em foco (Figura 1), no inverno foi selecionado o Ponto 9 como o mais representativo, o qual apresentou diferença relativa média de $-0,55 \%$ e desvio-padrão em torno de $3 \%$. Na primavera, o Ponto 5 mostrou-se mais preciso, com valores de diferença relativa média de -0,0139 \% e desvio-padrão de $5 \%$. No verão, o Ponto 28 foi o mais preciso, com diferença relativa igual a - $0,1344 \%$ e desvio-padrão próximo a $5 \%$. Finalmente, no outono, o Ponto 31 sobressaiu, 
com diferença relativa de 0,429 \% e desvio-padrão em torno de $7 \%$. Com base nesses resultados, nota-se que os pontos selecionados para monitoramento contínuo da umidade do solo nas estações de primavera e verão apresentaram valores de desvio-padrão similares, enquanto no outono o desvio- padrão foi ligeiramente superior e, no inverno, a estação com o menor desvio-padrão no ponto selecionado. Nesse sentido, é possível concluir que o monitoramento durante o inverno, com base nos pontos selecionados, apresentará maior confiabilidade, seguido da primavera e do verão e, finalmente, do outono, devido a diferenças nos valores do desvio-padrão.

\section{CONCLUSÕES}

1. Houve diferença no padrão espacial da umidade do solo ao longo das estações do ano devido à amplitude significativa dos alcances dos modelos de semivariogramas ajustados, sugerindo que a estrutura de dependência espacial desse atributo físico do solo varia em função das características climáticas presentes na bacia.

2. Observou-se maior homogeneidade do padrão espacial da umidade do solo nas estações de verão e outono comparável ao inverno e à primavera, devido à maior similaridade dos semivariogramas escalonados. Isso mostra que no período em que a umidade do solo é menor (inverno e primavera) ocorre maior influência de fatores climáticos na estrutura de dependência espacial.

3. Constatou-se que o padrão temporal da umidade do solo variou em função das estações do ano, ressaltando-se que houve tendência temporal da série de umidade do solo no inverno e na primavera. Verificou-se também maior homogeneidade desse padrão nos períodos em que o solo apresentou maior umidade, com comportamento semelhante do desviopadrão entre os pontos amostrados.

4. Devido à variabilidade do padrão espaçotemporal entre as estações do ano, em cada estação foi identificado um ponto específico com características próximas à média da umidade do solo na bacia hidrográfica, e esses pontos mesmos podem ser indicados para implantação de monitoramento contínuo desse atributo físico do solo.

\section{AGRADECIMENTOS}

Ao CNPq, pela concessão de bolsa a todos os autores do trabalho; à CEMIG/ANEEL (P\&D 176) e à FAPEMIG (PPM IV 060/10), pelo suporte financeiro para a realização dos trabalhos de campo.

\section{LITERATURA CITADA}

AVILA, L.F.; MELLO, C.R. \& SILVA, A.M. Continuidade e distribuição espacial da umidade do solo numa Bacia Hidrográfica da Serra da Mantiqueira. R. Bras. Eng. Agríc. Amb., 14:1257-1266, 2010a.

AVILA, L.F.; MELLO, C.R. \& SILVA, A.M. Estabilidade temporal da umidade do solo em uma bacia hidrográfica na região da Serra da Mantiqueira, Minas Gerais. R. Bras. Ci. Solo, 34:2001-2009, 2010b.

BROCCA, L.; MORBIDELLI, R.; MELONE, F. \& MORAMARCO, T. Soil moisture spatial variability in experimental areas of central Italy. J. Hydrol., 333:356373,2007

CAMBARDELLA, C.A.; MOORMAN, T.B.; PARKIN, T.B.; KARLEN, D.L.; NOVAK, J.M.; TURCO, R.F. \& KONOPKA, A.E. Field scale variability of soil properties in Central Iowa soils. Soil Sci. Soc. Am. J., 58:1501-1511, 1994.

CAMPOS, H. Estatística experimental não-paramétrica. 4.ed. Piracicaba, ESALQ/FEALQ, 1983. 349p.

CANTON, Y.; SOLE'-BENET, A. \& DOMINGO, F. Temporal and spatial patterns of soil moisture in semiarid badlands of SE Spain. J. Hydrol., 285:199-214, 2004.

ENVIRONMENT FOR VISUALIZING IMAGES - ENVI. User guide. version 3.4, ed. Boulder, Research System, 2000. 930 .

FAMIGLIETTI, J.S.; RUDNICKI, J.W. \& RODELL, M. Variability in surface moisture content along a hillslope transect: rattlesnake hill, Texas. J. Hydrol., 210:259-281, 1998.

GÓMEZ-PLAZA, A.; ALVAREZ-ROGEL, J. \& ALBALADEJO, J. Spatial patterns and temporal stability of soil moisture across a range of scales in a semi-arid environment. Hydrol. Process, 14:1261-1277, 2000.

GOMEZ-PLAZA, A.; MARTINEZ-MENA, M.; ALBALADEJO, J. \& CASTILLO, V.M. Factors regulating spatial distribution of soil water content in small semiarid catchments. J. Hydrol., 253:211-226, 2001.

GRAYSON, R.B.; WESTERN, A.W.; CHIEW, H.S. \& BLO SCHL, G. Preferred states in spatial soil moisture pattern: local and non local controls. Water Res. Res., 33:28972908, 1997.

GREGO, C.R.; VIEIRA, S.R.; ANTONIO, A.M. \& DELLA ROSA, S.C. Geostatistical analysis for soil moisture content under the no tillage cropping system. Sci. Agric., 63:341350,2006

HÉBRARD, O.; VOLTZ, M.; ANDRIEUX, P. \& MOUSSA, R. Spatio-temporal distribution of soil surface moisture in a heterogeneously farmed Mediterranean catchment. J. Hydrol., 329:110-121, 2006.

ISAAKS, E.H. \& SRIVASTAVA, M. An introduction to applied geostatistics. New York, Oxford Univesity, 1989. 600p.

JOURNEL, A.G. \& HUIJBREGTS, C.J. Mining geostatistics. London, Academic Press, 1978. 600p. 
MELLO, C.R.; ÁVILA, L.F.; NORTON, L.D.; SILVA, A.M.; MELLO, J.M. \& BESKOW, S. Spatial distribution of top soil water content in an experimental catchment of Southeast Brazil. Sci. Agric., 68:265-393, 2011.

MELLO, C.R.; SÁ, M.A.C.; CURI, N.; MELLO, J.M.; VIOLA, M.R. \& SILVA, A.M. Erosividade mensal e anual da chuva no Estado de Minas Gerais. Pesq. Agropec. Bras., 42:537$545,2007$.

MOHANTY, B.P.; FAMIGLIETTI, J.S. \& SKAGGS, T.H. Evolution of soil moisture spatial structure in a mixed vegetation pixel during the Southern Great Plains 1997 (SGP97) Hydrology experiment. Water Res. Res., 36:36753686,2000 .

MOORE, I.D.; BURCH, G.J. \& MACKENZIE, D.H. Topographic effects on the distribution of surface water and the location of ephemeral gullies. Trans. ASAE, 31:1098-1107, 1998.

MOTTA, P.E.F.; CURI, N.; SILVA, M.L.N.; MARQUES, J.J.G.S.M.; PRADO, N.J.S. \& FONSECA, E.M.B. Levantamento pedológico detalhado, erosão dos solos, uso atual e aptidão agrícola das terras da microbacia piloto na região sob influência do reservatório da hidrelétrica de Itutinga/Camargos-MG. Belo Horizonte, CEMIG/UFLA/ FAEPE, 2001. 51p.

PAZ-GONZÁLEZ, A.; VIEIRA, S.R. \& TABOADA CASTRO, M.T. The effect of cultivation on the variability of selected properties of an umbric horizon. Geoderma, 97:273-292, 2000 .

QIU, Y.; FU, B.; WANG, J. \& CHEN, L. Soil moisture variation in relation to topography and land use in a hillslope catchment of the Loess Plateau, China. J. Hydrol., 240:243-263, 2001

R DEVELOPMENT CORE TEAM. R: A language and environment for statistical computing. R Foundation for Statistical Computing. Vienna, Austria. ISBN 3-90005107-0, URL http://www.R-project.org, 2010.

RIBEIRO JÚNIOR, P.J. \& DIGGLE, P.J. geoR: A package for geostatistical analysis. R-NEWS, 1:15-18, 2001.
TIMM, L.C.; PIRES, L.F.; ROVERATTI, R.; ARTHUR, R.C.J.; REICHARDT, K.; OLIVEIRA, J.C.M. \& BACCHI, O.O.S. Field spatial and temporal patterns of soil water content and bulk density changes. Sci. Agric., 63:55-64, 2006.

VACHAUD, G.; PASSERAT DE SILANS, A.; BALABANIS, P. $\&$ VAUCLIN, M. Temporal stability of spatially measured soil water probability density function. Soil Sci. Soc. Am. J., 49:822-827, 1985.

van den ELSEN, E.; XIE, Y.; LIU, B.; STOLT, J.; WU, Y.; TROUWBORST, K. \& RITZEMA, C.J. Intensive water content and discharge measurement system in a hillslope gully in China. Catena, 54:93-115, 2003.

VIEIRA, S.R. Geoestatística em estudos de variabilidade espacial do solo. In: NOVAIS, R.F.; ALVAREZ V., V.H. \& SCHAEFER, C.E.G.R., eds. Tópicos em ciência do solo. Viçosa, MG, Sociedade Brasileira de Ciência do Solo, 2000. v.1. p.2-54.

VIEIRA, S.R.; GARCIA, M.A.G.; PAZ-GONZÁLEZ, A. \& SIQUEIRA, G.M. Variabilidade espacial e temporal do teor de água do solo sob duas formas de uso. Bragantia, 69:181-190, 2010.

WESTERN, A.W. \& BLÖSCHL, G. On the spatial of soil moisture. J. Hydrol. , 217: 203-224, 1999.

WESTERN, A.W. \& BLÖSCHL, G. \& GRAYSON, R.B. Geoestatistical characterization of soil moisture patterns in a Tarrawarra catchment. J. Hydrol., 205:20-37, 1998.

WESTERN, A.W.; ZHOU, S.L.; GRAYSON, R.B.; MCMAHON, T.A.; BLÖSCHL, G. \& WILSON, D.J. Spatial correlation of soil moisture in small catchments and its relationship to dominant spatial hydrological processes. J. Hydrol., 286:113-114, 2004

ZHU, Y. \& SHAO, M. Variability and pattern of surface moisture on a small-scale hillslope in Liudaogou catchment on the northern Loess Plateau of China. Geoderma, 147:185-191, 2008. 